\title{
Enhanced Performance of Dye-Sensitized Solar Cells with Graphene/ZnO Nanoparticles Bilayer Structure
}

\author{
Chih-Hung Hsu, ${ }^{1,2}$ Cheng-Chih Lai, ${ }^{2}$ Lung-Chien Chen, ${ }^{1}$ and Po-Shun Chan ${ }^{1}$ \\ ${ }^{1}$ Department of Electro-Optical Engineering, National Taipei University of Technology, No. 1, Section 3, \\ Chung-Hsiao E. Road, Taipei 106, Taiwan \\ ${ }^{2}$ Bichen Technology Co., Ltd., 18F-3, No. 77, Section 1, Xintai 5th Road, Xizhi District, New Taipei City 22101, Taiwan
}

Correspondence should be addressed to Lung-Chien Chen; ocean@ntut.edu.tw

Received 27 March 2014; Accepted 19 May 2014; Published 9 June 2014

Academic Editor: Hongmei Luo

Copyright (C) 2014 Chih-Hung Hsu et al. This is an open access article distributed under the Creative Commons Attribution License, which permits unrestricted use, distribution, and reproduction in any medium, provided the original work is properly cited.

\begin{abstract}
This study reports characteristics of dye-sensitized solar cells (DSSCs) with graphene/ZnO nanoparticle bilayer structure. The enhancement of the performance of DSSCs achieved using graphene/ZnO nanoparticle films is attributable to the introduction of an electron-extraction layer and absorption of light in the visible range and especially in the range $300-420 \mathrm{~nm}$. DSSC that was fabricated with graphene/ZnO nanoparticle film composite photoanodes exhibited a $V_{\text {oc }}$ of $0.5 \mathrm{~V}$, a $J_{\mathrm{sc}}$ of $17.5 \mathrm{~mA} / \mathrm{cm}^{2}$, an $\mathrm{FF}$ of 0.456 , and a calculated $\eta$ of $3.98 \%$.
\end{abstract}

\section{Introduction}

Graphene has attracted much interest because of its unique properties and potential applications. As the thinnest 2D material, graphene has a high carrier mobility [1] and an excellent optical transparency [2]. Graphene and its derivatives have been used in transparent conductive films [3], as a new class of efficient hole- and electron-extraction materials [4-6], and in organic photovoltaic (PV) cells [7, 8]. Graphene films can be prepared using various techniques, including the micromechanical exfoliation of graphite [9], chemical vapor deposition (CVD) [10-14], the solution-based chemical reduction of graphene oxide to graphene [15-19], and magnetron sputtering, which has many advantages such as low cost, large scale, and ease of control.

The nanostructures of $\mathrm{ZnO}$ films can easily be tuned by modifying the growth solution and the use of ultrasonic spraying [20]. $\mathrm{ZnO}$ can also be tailored to various nanostructures, such as nanorods/nanowires [21-25], nanotubes [2427], nanoflowers [28], and nanosheets [29, 30], which have high electrical conductivity and enhanced photon absorption, supporting improved short-circuit current density and overall light conversion efficiency [31].

In this work, a graphene film with high electron mobility is incorporated into a $\mathrm{ZnO}$ nanoparticle film to form a compact layer for use in dye-sensitized solar cells. This investigation studies the optical, structural, and surface properties of a graphene film that is grown on ITO electrodes by radiofrequency magnetron sputtering, as functions of thickness, in high-performance DSSCs. The introduction of the sputtered graphene film (electron-extraction layer) with optimal thickness enhances the efficiency of conversion of the DSSCs.

\section{Experimental Setup}

In this study, a graphene film was prepared on ITO glass using a radio frequency magnetron sputtering system. Table 1 lists the typical deposition conditions for the graphene film. The resistivity of the graphene film is around $2.2 \times 10^{3} \mathrm{ohm}-\mathrm{cm}$. The $\mathrm{ZnO}$ nanoparticle film was deposited by ultrasonic spray pyrolysis at atmospheric pressure on ITO/graphene glass. Three aqueous solutions, $\mathrm{Zn}\left(\mathrm{CH}_{3} \mathrm{COO}\right)_{2} \cdot 2 \mathrm{H}_{2} \mathrm{O}(0.5 \mathrm{~mol} / \mathrm{l})$, $\mathrm{CH}_{3} \mathrm{COONH}_{4}(2.5 \mathrm{~mol} / \mathrm{l})$, and In $\left(\mathrm{NO}_{3}\right)_{3}(0.5 \mathrm{~mol} / \mathrm{l})$, were used as sources of zinc, nitrogen, and indium, respectively. The atomic ratio of $\mathrm{Zn} / \mathrm{N}$ in the $\mathrm{N}$-doped film was $1: 2$ and that of $\mathrm{Zn} / \mathrm{N} / \mathrm{In}$ in the N-In codoped film was $1: 2: 0.15$ [20]. An aerosol of the precursor solution was produced using a commercial ultrasonic nebulizer. Colloidal $\mathrm{TiO}_{2}$ was 
TABLE 1: Typical deposition conditions for graphene film.

\begin{tabular}{lc}
\hline Target & Graphite \\
Target diameter & $5 \mathrm{~cm}$ \\
Substrate-to-target distance & $4 \mathrm{~cm}$ \\
RF power & $90 \mathrm{~W}$ \\
Sputtering ambient & $\mathrm{Ar}$ \\
Gas flow rate & $90 \mathrm{sccm}$ \\
Residual pressure & $<5 \times 10^{-6} \mathrm{Torr}$ \\
Sputtering pressure & $3.1 \mathrm{mTorr}$ \\
Deposition time & $40 \mathrm{~min}$ \\
\hline
\end{tabular}

prepared from $6 \mathrm{~g}$ nanocrystalline powder (Degussa, P25 titanium oxide, Japan) and both $0.1 \mathrm{~mL}$ of Triton X-100 and $0.2 \mathrm{~mL}$ of acetylacetone, which were stirred together for $24 \mathrm{hrs}$. Subsequently, the mixture was spin-coated on ITO glass and ITO/graphene/ $\mathrm{ZnO}$ substrate to a thickness of approximately $15 \mu \mathrm{m}$, and a $3 \times 3 \mathrm{~mm}^{2}$ active area was defined. Thereafter, the prepared thin film photoelectrode was immersed in a $3 \times 10^{-4} \mathrm{M}$ Ru-metal complex dye, D719 ([RuL2(NCS)2]:2 TBA), at room temperature for $24 \mathrm{hrs,}$ before it was sintered at 450 or $500^{\circ} \mathrm{C}$ for $30 \mathrm{~min}$, to increase its anatase content (anatase : rutile $=85: 15$ ) [32]. The electrolyte included $0.05 \mathrm{M}$ iodide, $0.5 \mathrm{M}$ lithium iodide, and $0.5 \mathrm{M}$ 4-tert-butylpyridine (TBP) in propylene carbonate. A $100 \mathrm{~nm}$ thick layer of platinum was sputtered onto the ITO substrate to form a counter electrode. Cells were fabricated by placing sealing films between the two electrodes, leaving only two via-holes for injection of the electrolyte. The sealing process was performed on a hot plate at $100^{\circ} \mathrm{C}$ for $3 \mathrm{~min}$. Then, the electrolyte was injected into the space between the two electrodes through the via-holes. Finally, the via-holes were sealed using epoxy at a low vapor transmission rate. Figure 1 schematically depicts the complete structure.

A field emission scanning electron microscope (FESEM) (LEO 1530) was adopted to examine the cross-section and surface morphology of the cells. Additionally, the current density-voltage $(J-V)$ characteristics were measured using a Keithley 2420 programmable source meter under irradiation by a $1000 \mathrm{~W}$ xenon lamp. Finally, the irradiation power density on the surface of the sample was calibrated as $1000 \mathrm{~W} / \mathrm{m}^{2}$.

\section{Results and Discussion}

Figures 2(a) and 2(b) present the surface and cross-sectional FESEM images of the $\mathrm{ZnO}$ nanoparticle films on glass substrate. The surface images clearly reveal that $\mathrm{ZnO}$ nanoparticle films are highly dense and grown vertically on glass substrates, as shown in Figures 2(a) and 2(b). The highresolution image reveals that the obtained $\mathrm{ZnO}$ nanoparticle films exhibited hexagonal morphology with an average nanoparticle diameter of 300 330 nm. Figure 2(c) shows a typical X-ray diffraction (XRD) pattern of $\mathrm{ZnO}$ film. Three dominant diffraction peaks, $\mathrm{ZnO}(100)\left(2 \theta=31.76^{\circ}\right)$, $\mathrm{ZnO}(002)\left(2 \theta=34.46^{\circ}\right)$, and $\mathrm{ZnO}(101)\left(2 \theta=36.27^{\circ}\right)$, are observed. That demonstrates a typical $\mathrm{ZnO}$ polycrystalline structure.

Figure 3 presents the absorption spectra of the $\mathrm{TiO}_{2}, \mathrm{ZnO}$ nanoparticle, and graphene/ZnO nanoparticle/ $/ \mathrm{TiO}_{2}$ films. The $\mathrm{ZnO}$ nanoparticle thin film yields a strong absorption peak at $\sim 380 \mathrm{~nm}$, revealing the existence of crystalline wurtzite hexagonal $\mathrm{ZnO}$. The DSSC with the graphene film clearly has higher absorption intensity than the DSSC without the graphene film in the visible range, and especially in the range $300-420 \mathrm{~nm}$.

Figure 4 shows the XRD plots of the $\mathrm{TiO}_{2}$ film electrodes before and after annealing. The $\mathrm{TiO}_{2}$ films were dried in air at room temperature for $10 \mathrm{~min}$ and then annealing at $450^{\circ} \mathrm{C}$ for $30 \mathrm{~min}$. Two dominant anatase diffraction peaks, (101) $(2 \theta=$ $\left.25.28^{\circ}\right)$ and $(004)\left(2 \theta=37.73^{\circ}\right)$, are observed. Following annealing, the sample was highly crystalline and all of the diffraction peaks could be indexed to anatase $\mathrm{TiO}_{2}$.

In optoelectronic devices, proper contact between the electrode and the transporter (recombination and back transfer) is crucial for charge collection. Figure 5 presents the schematic energy level diagram of the DSSCs with the graphene and $\mathrm{ZnO}$ nanoparticle film. Graphene has a work function $(-4.42 \mathrm{eV}$ versus vacuum) similar to that of the ITO $(-4.8 \mathrm{eV}$ versus vacuum) electrode. The graphene does not prevent the flow of injected electrons down to the ITO electrode because its work function exceeds that of the ITO electrode [33-35]. Therefore, the implanted graphene collects electrons and acts as a transporter in the effective separation of charge and rapid transport of the photogenerated electrons.

Based on the above discussion, the incorporation of graphene into $\mathrm{ZnO}$ nanoparticle film enables DSSC devices to operate more efficiently. Figure 6 plots photocurrent $J-V$ curves of the DSSCs obtained under $100 \mathrm{~mW} / \mathrm{cm}^{2}$ illumination and the AM $1.5 \mathrm{G}$ condition without and with the graphene and $\mathrm{ZnO}$ nanoparticle film, fabricated on an ITO glass substrate. The cell has an active area of $3 \times 3 \mathrm{~mm}^{2}$ and no antireflective coating. Table 2 presents the measured cell parameters-open-circuit voltage $\left(V_{o c}\right)$, short-circuit current $\left(J_{\text {sc }}\right)$, fill factor $(\mathrm{FF})$, and energy conversion efficiency $(\eta)$. The DSSC that was fabricated with graphene/ $\mathrm{ZnO}$ nanoparticle film composite photoanodes exhibited a $V_{\text {oc }}$ of $0.5 \mathrm{~V}$, a $J_{\text {sc }}$ of $17.5 \mathrm{~mA} / \mathrm{cm}^{-2}$, an FF of 0.456 , and a calculated $\eta$ of $3.98 \%$. Incorporating graphene oxide into the graphene film effectively decreases the internal resistance within the photoanodes and prolonged the electron lifetime. Therefore, the improved photovoltaic properties of DSSC with the graphene/ZnO nanoparticle film photoanode are attributable to the strong absorption of dye and the high light harvesting efficiency, which reduce electron recombination loss.

\section{Conclusion}

This work discusses the improvement that is made by the introduction of a sputtered graphene/ $\mathrm{ZnO}$ nanoparticle film into DSSCs. The enhancement of the performance of DSSCs by the introduction of graphene/ $\mathrm{ZnO}$ nanoparticle films may be attributed to the introduction of an electron-extraction 


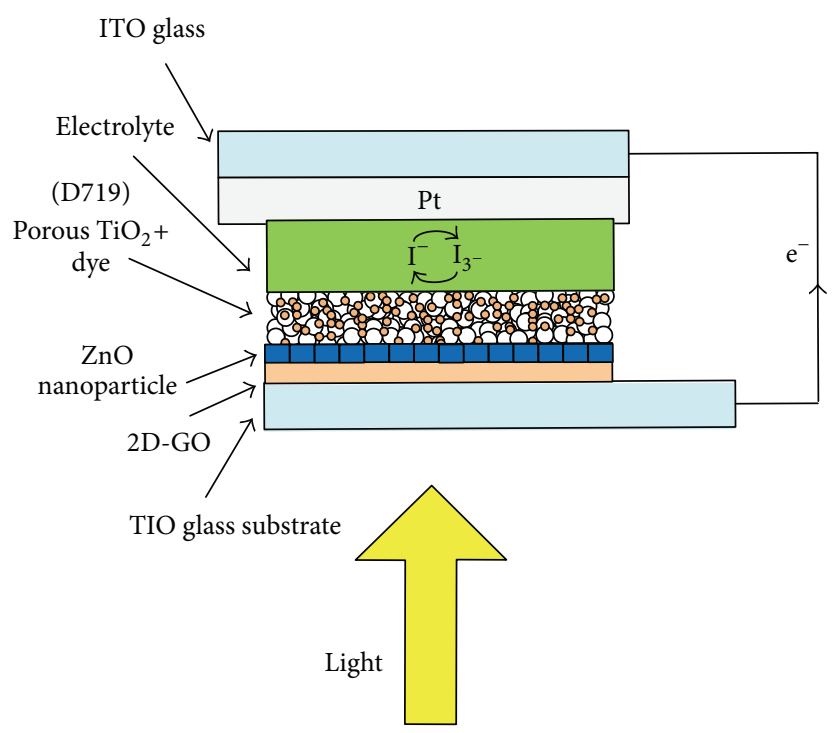

FIGURE 1: Schematic of DSSCs with graphene/ZnO nanoparticle film.

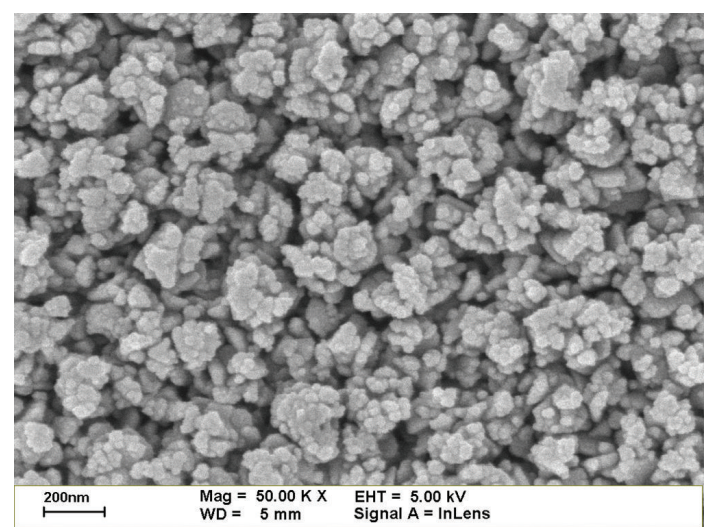

(a)

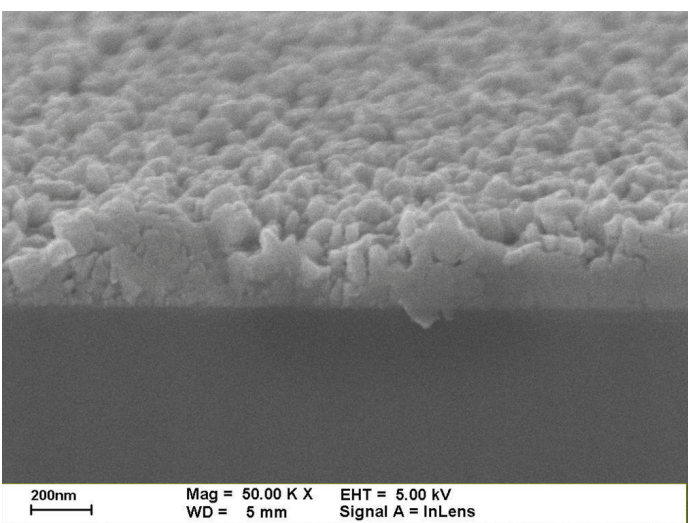

(b)

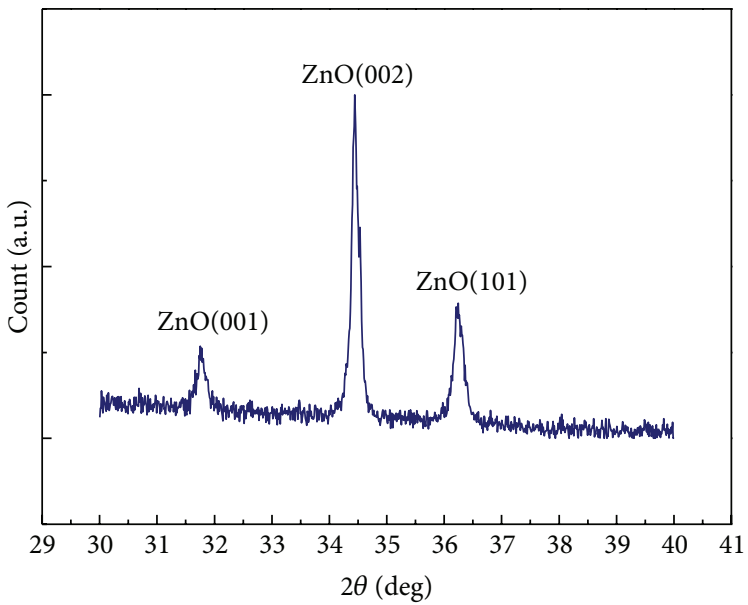

(c)

FIGURE 2: (a) FESEM surface image of photoanode with $\mathrm{ZnO}$ nanoparticle film. (b) FESEM cross-section image of $\mathrm{ZnO}$ nanoparticle film. (c) XRD pattern of $\mathrm{ZnO}$ nanoparticles film. 
TABLE 2: Parameters of $\mathrm{TiO}_{2}$ DSSCs with and without the graphene and $\mathrm{ZnO}$ nanoparticle film, fabricated on bare ITO glass substrate.

\begin{tabular}{lccc}
\hline & $\mathrm{ITO} / \mathrm{TiO}_{2}$ & $\begin{array}{c}\mathrm{ITO} / \mathrm{ZnO} \\
\text { nanoparticle/TiO }\end{array}$ & $\begin{array}{c}\mathrm{ITO} / \mathrm{graphene} / \mathrm{ZnO} \\
\text { nanoparticle/TiO }\end{array}$ \\
\hline$J_{\text {sc }}\left(\mathrm{mA} / \mathrm{cm}^{2}\right)$ & 6.9 & 11.3 & 17.5 \\
$V_{\text {oc }}(\mathrm{V})$ & 0.5 & 0.45 & 0.5 \\
F.F. & 0.419 & 0.473 & 0.456 \\
Efficiency & 1.45 & 2.4 & 3.98 \\
\hline
\end{tabular}

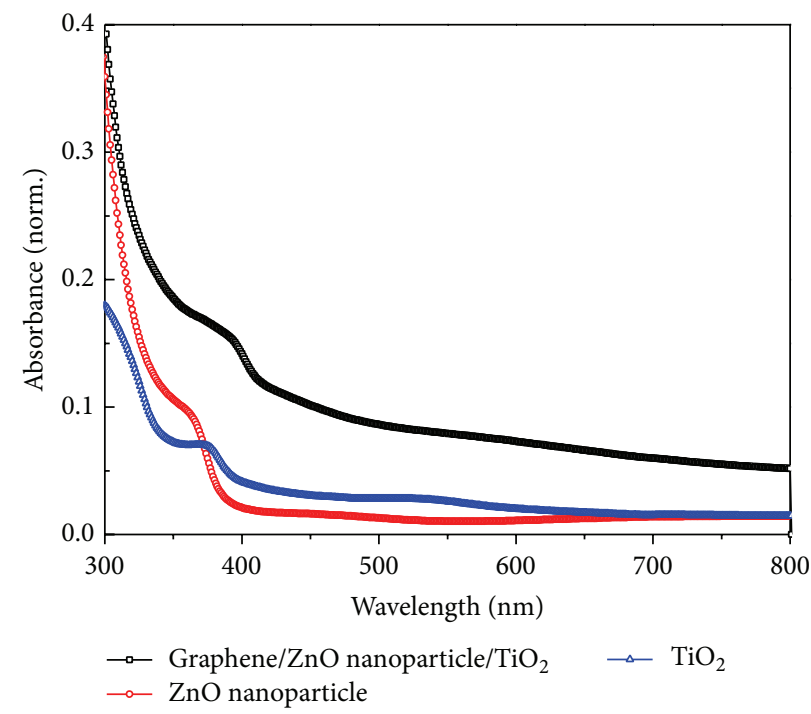

Figure 3: Absorbance spectra of $\mathrm{TiO}_{2}, \mathrm{ZnO}$ nanoparticle, and graphene/ $\mathrm{ZnO}$ nanoparticle/TiO 2 film.

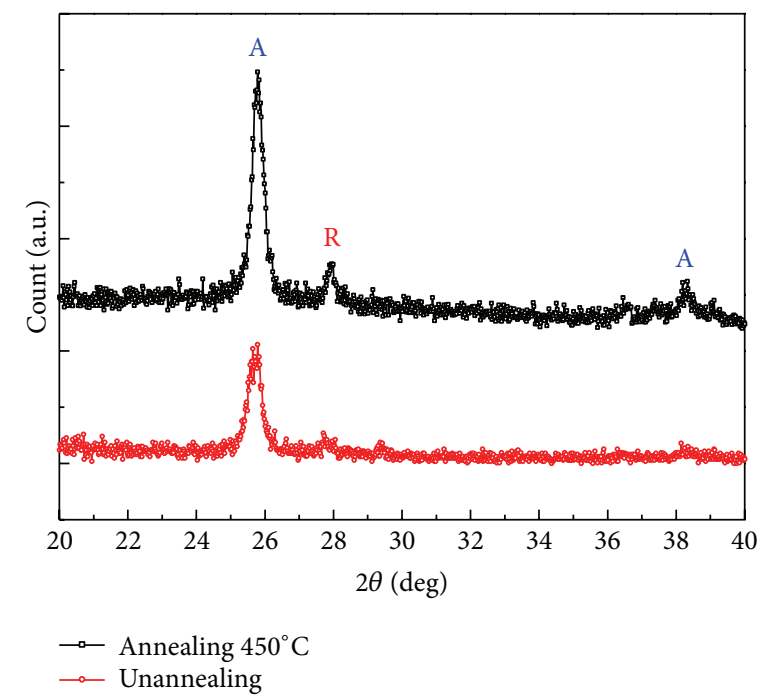

FIGURE 4: XRD pattern of $\mathrm{TiO}_{2}$ on glass substrate (A: anatase, R: rutile).

layer and the absorption of light in the visible range, especially in the range $300-420 \mathrm{~nm}$. A DSSC that was fabricated with graphene/ZnO nanoparticle film composite photoanodes had a $V_{\text {oc }}$ of $0.5 \mathrm{~V}$, a $J_{\mathrm{sc}}$ of $17.5 \mathrm{~mA} / \mathrm{cm}^{-2}$, an $\mathrm{FF}$ of 0.456 , and a calculated $\eta$ of $3.98 \%$. Accordingly, the improvement of photovoltaic properties of DSSC by the introduction of the graphene/ $\mathrm{ZnO}$ nanoparticle film photoanode is attributable to the strong absorption of dye and the high light harvesting efficiency, which can reduce the electron recombination loss. The above results demonstrate the potential application of 


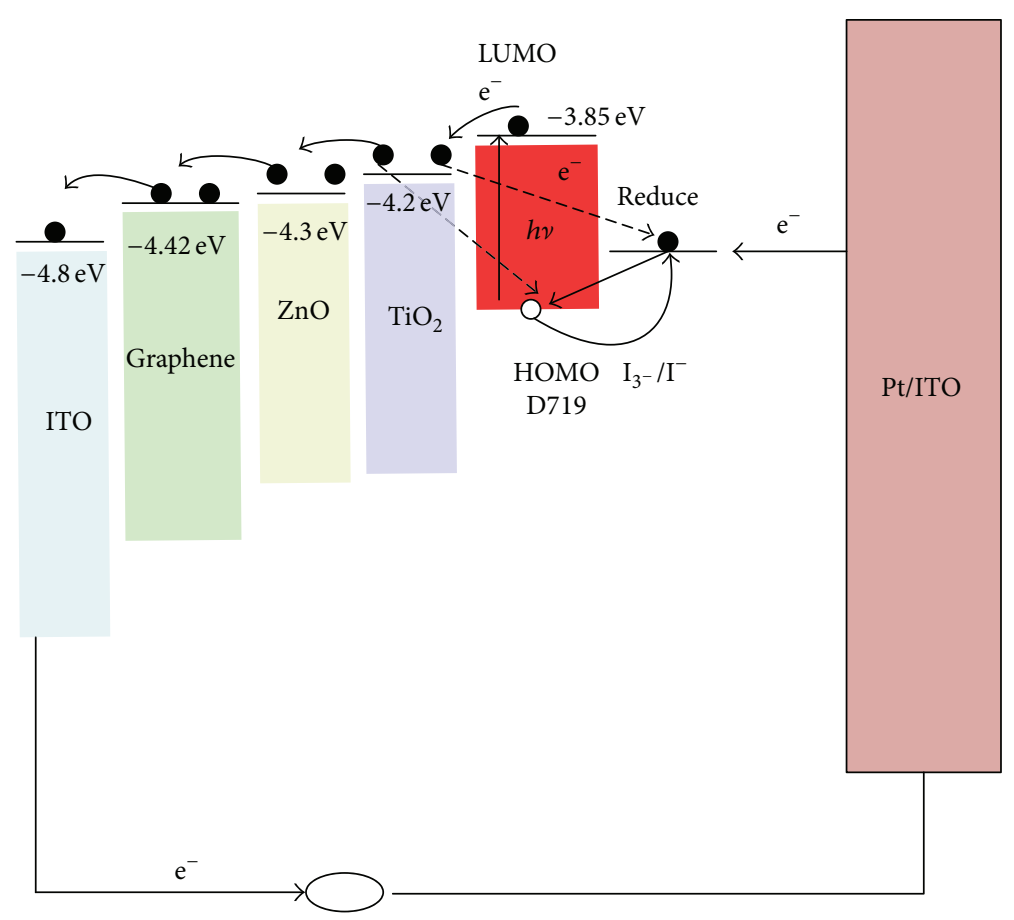

FIGURE 5: Energy level diagram and mechanism of photocurrent generation in DSSCs with GO and ZnO nanoparticles.

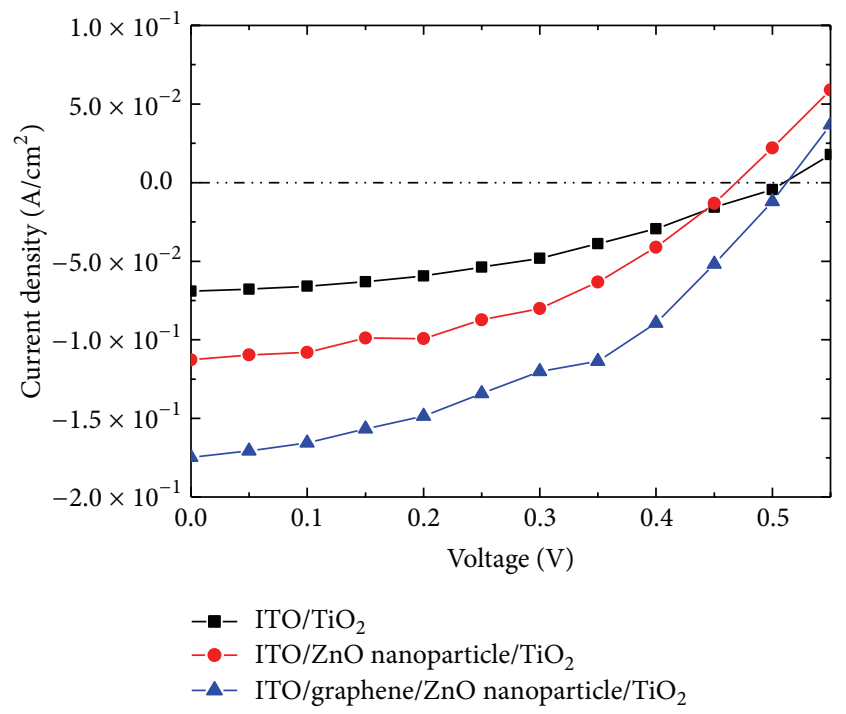

FIgURE 6: Current-voltage $(J-V)$ characteristics of DSSCs fabricated with ITO/graphene/ZnO nanoparticle/ $/ \mathrm{TiO}_{2}$ photoanodes under simulated illumination by a light intensity of $100 \mathrm{~mW} / \mathrm{cm}^{2}$ (AM 1.5).

graphene oxide to improve for enhancing the performance of $\mathrm{ZnO}$ nanoparticle-based DSSCs, which can be produced on a large scale at low cost.

\section{Conflict of Interests}

The authors declare that there is no conflict of interests regarding the publication of this paper.

\section{Acknowledgment}

Financial support of this paper was provided by the National Science Council of the Republic of China under Contract no. NSC 102-2622-E-027-021-CC3.

\section{References}

[1] X. Du, I. Skachko, A. Barker, and E. Y. Andrei, "Approaching ballistic transport in suspended graphene," Nature Nanotechnology, vol. 3, no. 8, pp. 491-495, 2008.

[2] R. R. Nair, P. Blake, A. N. Grigorenko et al., "Fine structure constant defines visual transparency of graphene," Science, vol. 320, no. 5881, p. 1308, 2008.

[3] S. Bae, H. Kim, Y. Lee et al., "Roll-to-roll production of 30-inch graphene films for transparent electrodes," Nature Nanotechnology, vol. 5, no. 8, pp. 574-578, 2010.

[4] J. Liu, Y. Xue, Y. Gao, D. Yu, M. Durstock, and L. Dai, "Hole and electron extraction layers based on graphene oxide derivatives for high-performance bulk heterojunction solar cells," Advanced Materials, vol. 24, no. 17, pp. 2228-2233, 2012.

[5] J. Liu, Y. Xue, and L. Dai, "Sulfated graphene oxide as a hole-extraction layer in high-performance polymer solar cells," Journal of Physical Chemistry Letters, vol. 3, no. 14, pp. 19281933, 2012.

[6] X. Wang, L. Zhi, N. Tsao, Ž. Tomović, J. Li, and K. Müllen, "Transparent carbon films as electrodes in organic solar cells," Angewandte Chemie-International Edition, vol. 47, no. 16, pp. 2990-2992, 2008.

[7] X. Wang, L. Zhi, and K. Müllen, "Transparentconductive graphene electrodes for dye-sensitized solar cells," Nano Letters, vol. 8, no. 1, pp. 323-327, 2007. 
[8] K. S. Novoselov, A. K. Geim, S. V. Morozov et al., "Electric field in atomically thin carbon films," Science, vol. 306, no. 5696, pp. 666-669, 2004.

[9] C. Berger, Z. Song, T. Li et al., "Ultrathin epitaxial graphite: $2 \mathrm{D}$ electron gas properties and a route toward graphene-based nanoelectronics," Journal of Physical Chemistry B, vol. 108, no. 52, pp. 19912-19916, 2004.

[10] A. Dato, V. Radmilovic, Z. Lee, J. Phillips, and M. Frenklach, "Substrate-free gas-phase synthesis of graphene sheets," Nano Letters, vol. 8, no. 7, pp. 2012-2016, 2008.

[11] K. S. Kim, Y. Zhao, H. Jang et al., "Large-scale pattern growth of graphene films for stretchable transparent electrodes," Nature, vol. 457, no. 7230, pp. 706-710, 2009.

[12] A. Reina, X. Jia, J. Ho et al., "Large area, few-layer graphene films on arbitrary substrates by chemical vapor deposition," Nano Letters, vol. 9, no. 1, pp. 30-35, 2009.

[13] P. W. Sutter, J.-I. Flege, and E. A. Sutter, "Epitaxial graphene on ruthenium," Nature Materials, vol. 7, no. 5, pp. 406-411, 2008.

[14] D. Li, M. B. Müller, S. Gilje, R. B. Kaner, and G. G. Wallace, "Processable aqueous dispersions of graphene nanosheets," Nature Nanotechnology, vol. 3, no. 2, pp. 101-105, 2008.

[15] S. Park and R. S. Ruoff, "Chemical methods for the production of graphenes," Nature Nanotechnology, vol. 4, no. 4, pp. 217-224, 2009.

[16] S. Stankovich, D. A. Dikin, R. D. Piner et al., "Synthesis of graphene-based nanosheets via chemical reduction of exfoliated graphite oxide," Carbon, vol. 45, no. 7, pp. 1558-1565, 2007.

[17] V. C. Tung, M. J. Allen, Y. Yang, and R. B. Kaner, "Highthroughput solution processing of large-scale graphene," Nature Nanotechnology, vol. 4, no. 1, pp. 25-29, 2009.

[18] J. Zhang, H. Yang, G. Shen, P. Cheng, J. Zhang, and S. Guo, "Reduction of graphene oxide vial-ascorbic acid," Chemical Communications, vol. 46, no. 7, pp. 1112-1114, 2010.

[19] L. C. Chen, C. H. Tien, and C. S. Fu, "Magneto-optical characteristics of $\mathrm{Mn}$-doped $\mathrm{ZnO}$ films deposited by ultrasonic spray pyrolysis," Materials Science in Semiconductor Processing, vol. 15, pp. 80-85, 2012.

[20] M. Law, L. E. Greene, J. C. Johnson, R. Saykally, and P. Yang, "Nanowire dye-sensitized solar cells," Nature Materials, vol. 4, no. 6, pp. 455-459, 2005.

[21] J. B. Baxter and E. S. Aydil, "Nanowire-based dye-sensitized solar cells," Applied Physics Letters, vol. 86, no. 5, Article ID 053114, 2005.

[22] A. Du Pasquier, H. Chen, and Y. Lu, "Dye sensitized solar cells using well-aligned zinc oxide nanotip arrays," Applied Physics Letters, vol. 89, no. 25, Article ID 253513, 2006.

[23] H.-M. Cheng, W.-H. Chiu, C.-H. Lee, S.-Y. Tsai, and W.-F. Hsieh, "Formation of branched $\mathrm{ZnO}$ nanowires from solvothermal method and dye-sensitized solar cells applications," Journal of Physical Chemistry C, vol. 112, no. 42, pp. 16359-16364, 2008.

[24] I. Gonzalez-Valls and M. Lira-Cantu, "Vertically-aligned nanostructures of $\mathrm{ZnO}$ for excitonic solar cells: a review," Energy and Environmental Science, vol. 2, no. 1, pp. 19-34, 2009.

[25] A. B. F. Martinson, J. W. Elam, J. T. Hupp, and M. J. Pellin, "ZnO nanotube based dye-sensitized solar cells," Nano Letters, vol. 7, no. 8, pp. 2183-2187, 2007.

[26] A. B. F. Martinson, M. S. Goes, F. Fabregat-Santiago, J. Bisquert, M. J. Pellin, and J. T. Hupp, "Electron transport in dye-sensitized solar cells based on zno nanotubes: evidence for highly efficient charge collection and exceptionally rapid dynamics," Journal of Physical Chemistry A, vol. 113, no. 16, pp. 4015-4021, 2009.
[27] C. Y. Jiang, X. W. Sun, G. Q. Lo, D. L. Kwong, and J. X. Wang, "Improved dye-sensitized solar cells with a $\mathrm{ZnO}$-nanoflower photoanode," Applied Physics Letters, vol. 90, no. 26, Article ID 263501, 2007.

[28] E. Hosono, S. Fujihara, I. Honma, and H. Zhou, "The fabrication of an upright-standing zinc oxide nanosheet for use in dyesensitized solar cells," Advanced Materials, vol. 17, no. 17, pp. 2091-2094, 2005.

[29] E. Hosono, Y. Mitsui, and H. Zhou, "Metal-free organic dye sensitized solar cell based on perpendicular zinc oxide nanosheet thick films with high conversion efficiency," Dalton Transactions, vol. 28, no. 40, pp. 5439-5441, 2008.

[30] E. M. Kaidashev, M. Lorenz, H. von Wenckstern et al., "High electron mobility of epitaxial $\mathrm{ZnO}$ thin films on c-plane sapphire grown by multistep pulsed-laser deposition," Applied Physics Letters, vol. 82, no. 22, pp. 3901-3903, 2003.

[31] C.-C. Wang and J. Y. Ying, "Sol-gel synthesis and hydrothermal processing of anatase and rutile titania nanocrystals," Chemistry of Materials, vol. 11, no. 11, pp. 3113-3120, 1999.

[32] R. Czerw, B. Foley, D. Tekleab, A. Rubio, P. M. Ajayan, and D. L. Carroll, "Substrate-interface interactions between carbon nanotubes and the supporting substrate," Physical Review B, vol. 66, no. 15, Article ID 033408, pp. 334081-334084, 2002.

[33] A. Andersson, N. Johansson, P. Bröms, N. Yu, D. Lupo, and W. R. Salaneck, "Fluorine tin oxide as an alternate to indium tin oxide in polymer LEDs," Advanced Materials, vol. 10, no. 11, pp. 859-863, 1998.

[34] A. Kongkanand, R. M. Domínguez, and P. V. Kamat, "Single wall carbon nanotube scaffolds for photoelectrochemical solar cells. Capture and transport of photogenerated electrons," Nano Letters, vol. 7, no. 3, pp. 676-680, 2007.

[35] F. Xu, J. Chen, X. Wu et al., "Graphene scaffolds enhanced photogenerated electron transport in $\mathrm{ZnO}$ photoanodes for high-efficiency dye-sensitized solar cells," Journal of Physical Chemistry C, vol. 117, no. 17, pp. 8619-8627, 2013. 

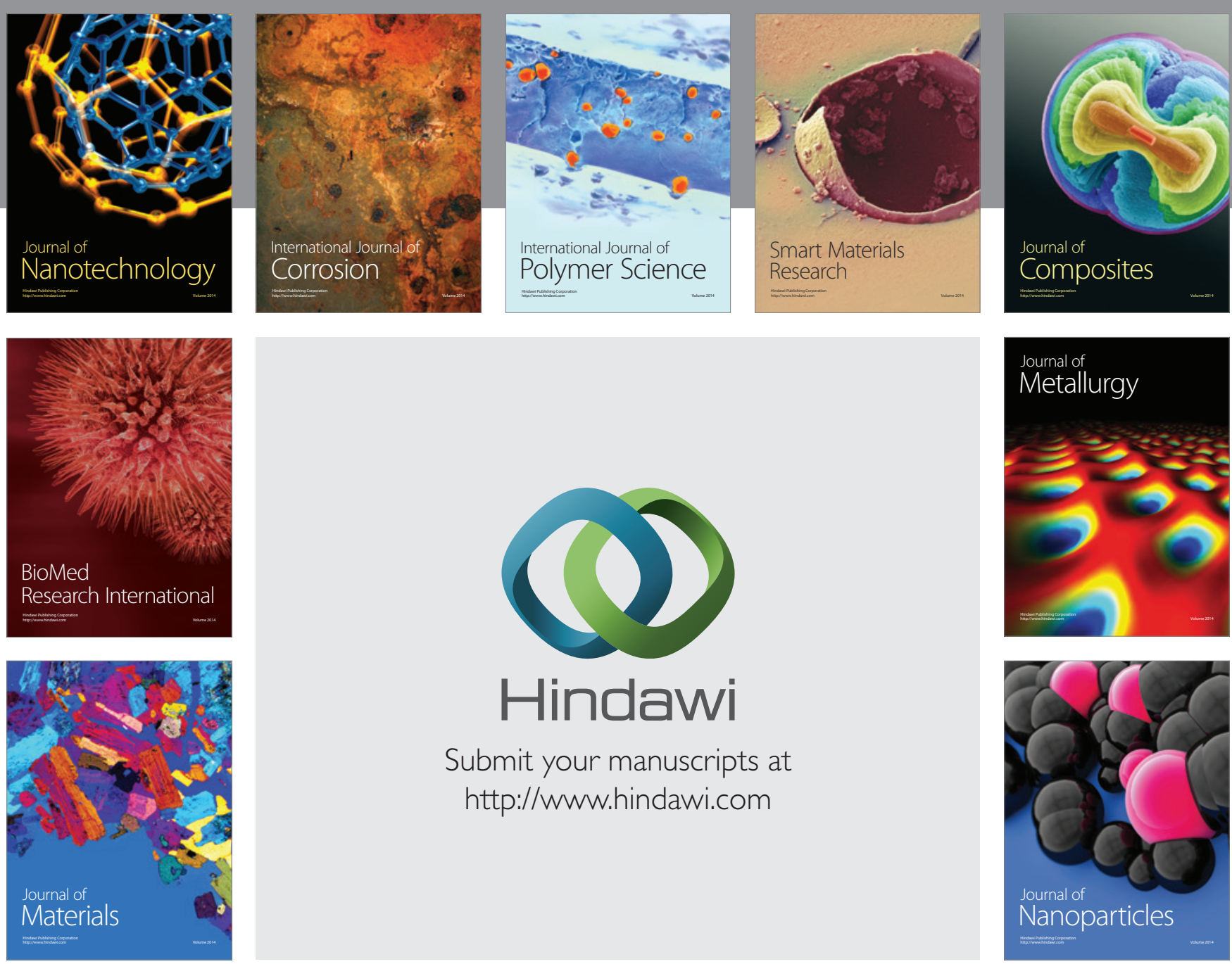

Submit your manuscripts at http://www.hindawi.com
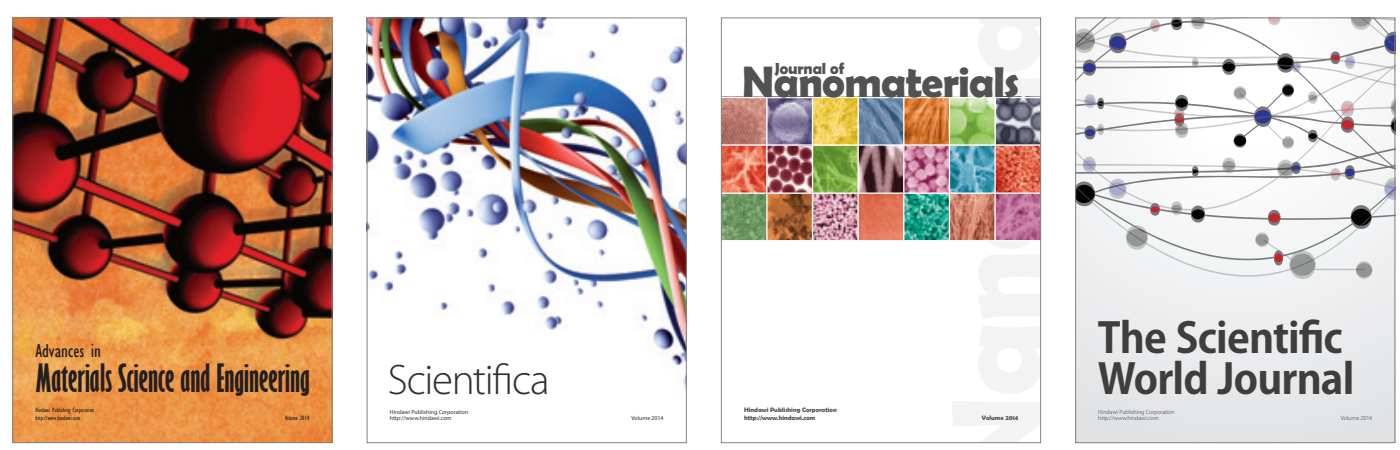

\section{The Scientific World Journal}
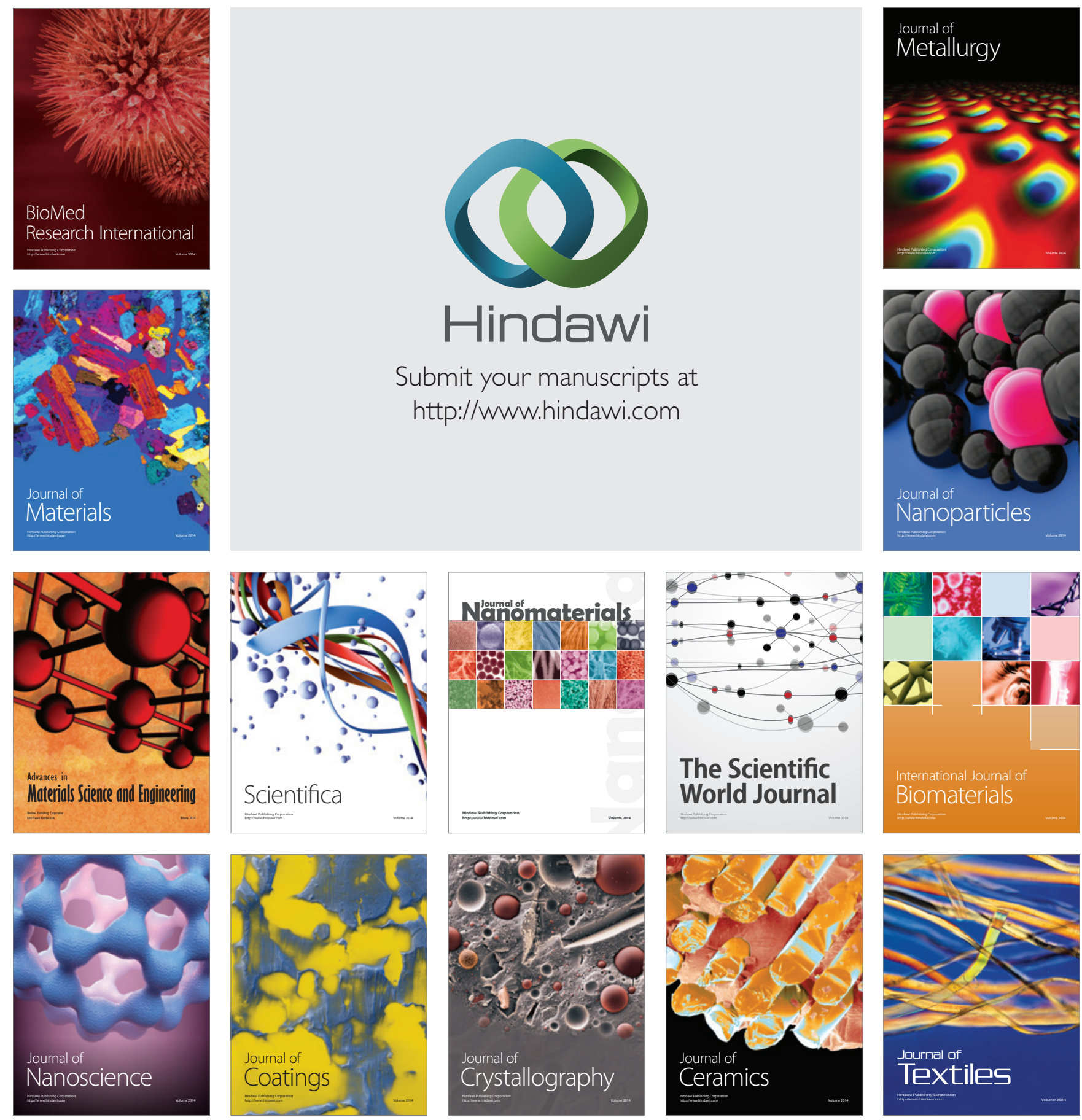